\title{
The identification process in Early Communication Intervention (ECl) by Primary Health Care personnel in Ditsobotla sub-district.
}

\author{
Jeannie van der Linde, Alta Kritzinger, Aniei \\ Redelinghuys \\ University of Pretoria
}

\begin{abstract}
Based on clinical observations, case finding for early communication intervention service delivery in rural areas, such as Ditsobotla sub-district, is limited. The study described the identification process used for infants and young children at risk for communication delay and disorders as part of a proposed incremental implementation of early communication intervention services within the existing primary health care package. A descriptive survey design was followed. A rating scale was utilized and interviews were conducted with 20 randomly selected primary health care personnel and eight primary health care programme managers in Ditsobotla sub-district in North West province. The aims were to describe the early identification methods/processes, resources and limitations and provide guidelines to introduce early communication in tervention services in a rural community. The results indicated that the identification process was limited. An incremental implementation of the different early communication intervention functions within the primary health care package appears feasible. Implications of the findings may be applied to initiate early communication intervention services, based on integrated teamwork, in a rural district in South Africa.
\end{abstract}

Key words: early communication intervention, early identification, referral systems, case finding, infants and young children, at-risk, communication delay or disorders, primary health care

$\mathrm{R}$ ural communities in South Africa particularly bear a high burden of disability, which may be both the cause and the consequence of poverty (Emmett, 2005). Infants at risk of developmental delay and their families who live in poverty therefore face additional constraints that place them at increased risk for developmental disabilities (Moodley, 1999). Due to a worldwide increase in developmental disabilities in children under three years (Rossetti, 2001), it can be expected that the number of young children presenting with communication delay and disorders will also increase.

Multiple risks of communication delay and disorders in young children occur in the rural sub-district of Ditsobotla in the North West province. From January to March 2005, 511 infants were born in the local hospitals and approximately $18 \%$ of them weighed less than $2500 \mathrm{~g}$ (Monthly Hospital Statistics, North West Province, 2005), which indicates low birth weight and a concomitant risk of developmental delay and disability (Rossetti, 2001). According to the same hospital statistics, $5 \%$ of the mothers were adolescents, which poses a risk for maladaptive parenting and poverty if they are not supported by other women (Werner, 2000) and $2.5 \%$ of the mothers had syphilis, a risk of bilateral sensorineural hearing loss of sudden onset and progression in their infants (Plante \& Beeson, 2004). Approximately $5 \%$ of the infants were born to mothers with HIV/AIDS (Monthly Hospital Statistics, North West Province, 2005), with a risk of mother-to-child transmission of the virus, and further risks of health and developmen- tal difficulties, congenital hearing loss or the development of hearing impairment shortly after birth (Swanepoel, 2004). Despite the different risk conditions and the clear indication to establish a sustainable early communication intervention $(\mathrm{ECI})$ programme in the sub-district, very few infants at risk were identified and referred to the first author during a year of community service employment.

Based on the one example of ECl services in South Africa not sufficiently meeting the needs of the mother and infant risk population, and a call from various authors to expand service delivery to include community-based ECl services (Kritzinger \& Louw, 2003; Moodley, 1999; Pickering et al., 1998), a research project was launched (Van der Linde, 2008). The aim was to investigate the existing identification and referral practices used in primary health care (PHC) services of the specific subdistrict in order to determine needs and resources that should be considered when developing $\mathrm{ECl}$ services.
Contact: Prof. Alta Kritzinger

Department of Communication

Pathology University of Pretoria Pretoria

e-mail: alta.kritzinger@up.ac.za 
THE IDENTIFICATION PROCESS IN EARLY COMMUNICATION INTERVENTION
underpinnings for the research study were based on eviThe under that emerged over time in the field of early intervention. The efficacy of eariy intervention was shown to be linked to the child's age at identification (Rossetti, 2001). If under three years of age, the window of opportunity may be enhanced by neurodevelopmental plasticity (Dennis, 2000). Early identification of risk conditions in infants should therefore be the primary function of ECl (Kritzinger, Louw \& Rossetti, 2001). Developing and implementing effective identification strategies, especially in rural areas, is one of the biggest challenges in $\mathrm{ECl}$, as a lack of identification will compromise the efficiency of the services (Kritzinger, 2000). Consequently, the efficacy of early identification of an infant at risk of developmental delay depends on a reliable referral system so that time delays between the detection of a problem and intervention services to the family may be minimised.

Furthermore, the efficacy of a referral system is in direct relation to the outcomes that the system achieves (Equity Project, 2000). By means of a smoothly functioning referral system the $\mathrm{ECl}$ client and family, for example, receives diagnostic and therapeutic services from a specialised team of medical and rehabilitative professionals, ensuring that $\mathrm{PHC}$ is more unified and financially sustainable (Equity Project, 2000; North West Department of Health, 2003). It appears that limited referrals and improper coordination of referral systems are partially responsible for $\mathrm{ECl}$ and its benefits being unknown in the South African health care system (Kritzinger, 2000).

Integrating $\mathrm{ECl}$ services into $\mathrm{PHC}$ in rural communities in South Africa has been recommended in various studies (Fair \& Louw, 1999; Kritzinger \& Louw, 2003; Moodley, 1999). Formalised by Rossetti in 1996, the concept of communication-based services to the population of children birth to three years of age, is based on the finding that communication delay is the most prevalent characteristic of delayed development in children in this age group (Rossetti, 2001). Enhancing communication development should therefore be the main focus of any effective early intervention programme (Rossetti, 2001) - hence the term early communication intervention.

In the planning and management of ECl services, the focus should be to develop strategies to prevent communication disorders in all people, including rural and disadvantaged communities (Kritzinger, 2000). As prevention of disability and communication disorders is the ultimate goal in $\mathrm{ECl}$, primary prevention programmes could be implemented at PHC clinics.

A transdisciplinary framework for $\mathrm{ECl}$ public service delivery has been proposed by Kritzinger and Louw (2003), which may be integrated into the PHC package of the Department of Health (2000). The PHC package was designed to provide comprehensive and integrated health services and not to be implemented through separate, vertical programmes where services are split according to disciplines, resulting in barriers to teamwork (van Rensburg, 2004). Consisting of eight different programmes, the package entails a standardised and comprehensive 'basket' of preventative, promotive, basic curative, rehabilitative and palliative services delivered at district level (Department of Health, 2000). Linked together as a service delivery model for health care, there are eight programmes i.e., 1) Non-personal health services (occupational and environmental health); 2) Disease prevention and control; 3) Maternal, child and women's health; 4) HIV/AIDS, sexually transmitted infections and tuberculosis; 5) Health monitoring and evaluation; 6) Mental health and substance abuse; 7) Gender issues, and 8) School health services. These should be mutually supported by the health care professionals delivering these services (Department of Health, 2000; Van Rensburg, 2004). Since teamwork is an essential approach in the implementation of the PHC package, the opportunity for collaboration should be utilised by therapists to introduce $\mathrm{ECl}$ services in communities.

The transdisciplinary conceptual framework for $\mathrm{ECl}$ describes collaborative partnerships with parents and caregivers, community health nurses and doctors, speech-language therapists, audiologists at PHC clinics, and secondary caregivers at créches and day-care facilities (Kritzinger \& Louw, 2003). According to Kritzinger and Louw (2003) ECl service delivery may be introduced to be consistent with the developmental stages of young children and the contexts where caregivers can be reached. Examples include services to the mother at antenatal clinics before the infant is born (providing preventative information on normal hearing and communication development); during the neonatal period in the postnatal ward (promoting mother-infant attachment and interaction, hearing screening and identifying risks for communication delay); during the postnatal period at immunization clinics (follow-up hearing screening, identifying further risks and provide $\mathrm{ECl}$, advocacy for education); and during the toddler years at day-care centres and nursery schools (providing ECl, training parents, facilitating a language and emergent literacyrich preschool curriculum to facilitate school readiness) (Kritzinger \& Louw, 2003).

With the exception of non-personal health services, integrating direct $\mathrm{ECl}$ services into seven of the different PHC programmes appears to be possible. The wide-ranging $\mathrm{ECl}$ functions such as promotion of normal development, prevention of feeding difficulties, hearing loss and communication disorders, parent training, screening, early identification and providing assessment and intervention correspond with the different services provided within the variety of programmes in the PHC package. If certain $\mathrm{ECl}$ functions are shared among professionals in PHC, case finding of infants at risk for communication delays or disorders may be improved and appropriate ECl services may be rendered to families at PHC facilities. Examples of successful integration of 
Jeannie van der Linde, Alta Kritzinger, Aniel Redelinghuys

paediatric health and developmental services in $\mathrm{PHC}$ can be found (Lequerica, 1997). According to Lequerica (1997) it appears that such a one-stop PHC service delivery model is preferred by families, and increases family participation. It is therefore important to investigate the feasibility of the integration of $\mathrm{PHC}$ and $\mathrm{ECl}$ programmes in a South African context where $\mathrm{ECl}$ services are lacking.

Since the primary goal of research is to improve understanding of a phenomenon (Leedy \& Ormrod, 2005), information produced by the current research study aims to identify certain problem areas. The research may also provide guidelines for identification and referral practices for $\mathrm{ECl}$ in the PHC context, which may be used to improve case finding in rural areas in South Africa. The information gathered through the research may also support the facilitation of a transdisciplinary team approach to service delivery in $\mathrm{ECl}$ in Ditsobotla sub-district, where effective collaboration between the PHC nurses, speech-language therapists, audiologists, and $\mathrm{PHC}$ programme managers may be established.

\section{METHOD}

\section{Aims and Objectives}

The purpose of the study was to describe the characteristics of identification methods and referral practices for $\mathrm{ECl}$ currently followed by PHC personnel in the Ditsobotla sub-district. The following objectives were formulated:

( To describe the features of the facilities in the PHC context in order to determine the capacity for implementing an $\mathrm{ECl}$ programme for infants with risks for disabilities.

To describe the human resources available in order to determine the needs within the PHC context.

To describe the early identification methods and resources currently used by the PHC personnel and managers to detect health problems as well as developmental delay and disabilities in infants.

To describe the referral systems, between different organizational departments in one facility, and the networks between different institutions, which are currently being used by $\mathrm{PHC}$ personnel for $\mathrm{ECl}$ services.

$\square \quad$ To describe the PHC programme managers' views on how to implement an early identification and referral programme for infants with risks for disabilities and delays in an integrated $\mathrm{PHC}$ and $\mathrm{ECl}$ approach.

\section{Research Design}

A descriptive research study was conducted. A dominant-lessdominant research design was selected, which entailed the use of a quantitative approach, the dominant component, and a qualitative approach, the smaller or less-dominant component
(Fouché \& De Vos, 2005). The quantitative approach implied a formalized approach with explicit control during data-collection (Fouché \& De Vos, 2005). A questionnaire and a rating scale were used as methods of data collection. The qualitative component consisted of semi-structured interviews with programme managers to obtain an in-depth understanding of data already collected and that may have needed further clarification (Leedy \& Ormrod, 2005).

To increase the reliability of the study, triangulation was used (De Vos, 2005). Triangulation results from a combination of qualitative and quantitative research approaches. It is based on the assumption that bias in a particular data source, investigator or method may be neutralized when used in combination with other data sources, investigators or methods (De Vos, 2005). In the current study both data triangulation, i.e. more than one data source - in this case the PHC sisters and the PHC programme managers- and methodological triangulation, i.e. multiple methods or approaches such as a rating scale and face-to-face interviews, were used (De Vos, 2005).

\section{Research Ethics}

The research proposal was approved by the Research Ethics and Proposal Committee of the Faculty of Humanities, University of Pretoria. Permission to conduct the research was granted by the North West Department of Health.

All participants gave voluntary informed consent to participate in the study. Information obtained from the participants was treated confidentially and reported anonymously. All efforts were made to conduct the research according to the ethical principles of no harm to participants, veracity, non-discrimination and sensitivity to cultural and language differences between participants and the researcher.

\section{Participants}

The two target populations were PHC personnel and PHC programme managers who were employed by Ditsobotla sub-district, which is part of the central district of North West Department of Health. Both groups had to be proficient in English in order to participate in the study. Although Setswana is the most commonly used language in the sub-district, it was found that the participants were sufficiently proficient in English to understand and answer the interview questions.

\section{Selection of participants}

Stratified random sampling was used to select the participants in group 1, the PHC personnel (Strydom \& Venter, 2002). Stratifications entailed that the specific population was divided in strata, which were homogeneous with regard to some characteristics (Strydom \& Venter, 2002). The entire PHC personnel of Ditsobotla sub-district were divided into two strata according to the size of the PHC facilities: all the clinics operating for 8 hours and 10 hours per day were part of stratum 1, while all the PHC hospitals 
THE IDENTIFICATION PROCESS IN EARLY COMMUNICATION INTERVENTION FOLLOWED BY PRIMARY HEALTH CARE PERSONNEL IN DITSOBOTLA SUB-DISTRICT

and 24-hour clinics were part of stratum 2. The selection within the strata was random (Strydom \& Venter, 2002) as the researcher randomly selected the facilities to be included in each stratum.

In group 2 all the PHC programme managers of Ditsobotla subdistrict who complied with the selection criteria received information brochures and were invited to participate. In this case the number of possible participants was limited. Non-random purposive sampling was used since a group of participants to represent the population did not have to be identified (Leedy \& Ormrod, 2005).

\section{Description of participants}

-Description of participants in Group 1: Approximately one third (20) of the PHC personnel in the entire sub-district were included in the study, with each stratum equally represented. The characteristics of the participants in group 1 are summarised in Table 1.

According to Table 1 there were only a few differences between the participants of the two strata. The majority of the participants had nursing diplomas, all were working on a full-time basis, with an average of eight to 12 years working experience. The participants therefore had work experience which rendered them as informed research participants, although three participants had no formal training.

Table 1. Characteristics of the participants in group $1(n=20)$

\begin{tabular}{|c|c|c|}
\hline Characteristic & Strata $1(n=10)$ & Strata $2(n=10)$ \\
\hline Qualification & $\begin{array}{l}\text { 2: B Cur Degree } \\
\text { 6: Diploma } \\
\text { 2: No formal train- } \\
\text { ing }\end{array}$ & $\begin{array}{l}\text { 3: B Cur Degree } \\
\text { 6: Diploma } \\
\text { 1: No formal train- } \\
\text { ing }\end{array}$ \\
\hline $\begin{array}{l}\text { Ýears of experi- } \\
\text { ence }\end{array}$ & $\begin{array}{l}4 \text { years - } 25 \text { years } \\
\text { Average: } 12,5 \text { years }\end{array}$ & $\begin{array}{l}1 \text { years }-26 \text { years } \\
\text { Average: } 8,4 \text { years }\end{array}$ \\
\hline First language & 10: Sețswana & $\begin{array}{l}\text { 9: Setswana } \\
\text { 1: Afrikaans }\end{array}$ \\
\hline $\begin{array}{l}\text { Employment } \\
\text { status }\end{array}$ & 10: Full-time & 10: Full-time \\
\hline $\begin{array}{l}\text { Type of facility } \\
\text { where employed }\end{array}$ & $\begin{array}{l}\text { 7: } 8 \text {-hour clinic } \\
\text { 3: } 12 \text {-hour clinic }\end{array}$ & $\begin{array}{l}\text { 2: PHC hospital } \\
\text { 8: } 24 \text {-hour clinic }\end{array}$ \\
\hline
\end{tabular}

\section{Description of participants in Group 2}

The participants in Group 2 represented more than two thirds of the total of the PHC programme managers. A total of $12 \mathrm{PHC}$ programme managers were working in Ditsobotla sub-district. All the programme managers were asked to participate, and a pilot study was conducted with one of the programme managers prior to the data collection. That left 11 PHC programme managers, eight of whom participated in the research. The other three potential participants were either on leave or were attending a course. The characteristics of the participants are summarised in Table 2.

According to Table 2 most of the programme managers had qualifications and work experience. A variety of programmes in the PHC package were represented by the managers, but those who managed the Maternal, child and women's health, Mental health and the HIV/AIDS programmes could not be included as participants as they were attending a course during the time allocated for data collection.

Table 2. Characteristics of the participants in group $2(n=8)$

\begin{tabular}{|c|c|c|c|c|c|}
\hline Qualifications & $\begin{array}{c}\text { Experi- } \\
\text { ence in } \\
\text { pro- } \\
\text { gramme } \\
\text { managing }\end{array}$ & $\begin{array}{l}\text { PHC facili- } \\
\text { ties visited }\end{array}$ & $\begin{array}{c}\text { First } \\
\text { lan- } \\
\text { guage }\end{array}$ & $\begin{array}{l}\text { Em- } \\
\text { ploy- } \\
\text { ment } \\
\text { status }\end{array}$ & $\begin{array}{c}\text { PHC pro- } \\
\text { gramme man- } \\
\text { aged }\end{array}$ \\
\hline $\begin{array}{l}\text { Masters de- } \\
\text { gree, B Cur } \\
\text { degree, nursing } \\
\text { diploma to no } \\
\text { formal training }\end{array}$ & $\begin{array}{l}\text { Range: } 1- \\
10 y \\
\text { Average: } \\
4 y\end{array}$ & $\begin{array}{l}\text { Hospitals } \\
\text { Clinics } \\
\text { Frail care } \\
\text { centres } \\
\text { Prisons } \\
\text { Hospices } \\
\text { Schools } \\
\text { Crèches } \\
\text { Business } \\
\text { premises }\end{array}$ & $\begin{array}{l}\text { 2: Afri- } \\
\text { kaans } \\
6: \\
\text { Setswa } \\
\text { na }\end{array}$ & $\begin{array}{l}\text { All Full- } \\
\text { time }\end{array}$ & $\begin{array}{l}\text { Geriatrics, } \\
\text { Chronic dis- } \\
\text { eases } \\
\text { Rehabilitation } \\
\text { Nutrition } \\
\text { Communicable } \\
\text { diseases } \\
\text { Occupational } \\
\text { therapy } \\
\text { Health promo- } \\
\text { tion } \\
\text { Nutrition } \\
\text { School health } \\
\text { Environmental } \\
\text { health }\end{array}$ \\
\hline
\end{tabular}

\section{Material and Apparatus}

The following material was exclusively developed for the data collection of the study:

A summated rating scale for the description of the facilities (See Appendix A).

Summated rating scales are widely used for the description of environments where phenomena have to be evaluated on a continuum of, for example, excellent to inadequate (Leedy \& Ormrod, 2005). The rating scale used was a means to analyse facilities and describe the available human resources. The rating scale provided not only the background to the study, but also relevant data which could point to strengths and weaknesses in the identification methods and referral systems of the PHC system in the Ditsobotla sub-district. The rating scale was also used to determine the capacity of the facilities to implement the different $\mathrm{ECl}$ functions.

The content of the rating scale included the following physical characteristics: water and electricity supply, the educational atmosphere of the waiting rooms, developmental screening materials available, space for interviews and screening assessments, filing cabinets and filing system. 
The human resources and services to infants were also recorded for each study site. Face-to-face interviews to investigate the identification processes used by the participants in Group 1

A structured interview was used to collect data on the identification processes, which included questions on the identification methods and the referral systems used by PHC personnel to identify and refer infants with developmental disorders or who are at risk for developmental delay. When the focus of a study is to investigate a process, in this case the identification process, structured interviews are especially suitable (Greeff, 2002). Although participants may not be as truthful in their responses as in the case of self-administered questionnaires, face-to-face interviews have the advantage of the highest response rate in survey research (Leedy \& Ormrod, 2005).

Face-to-face interviews with the participants in Group 2 on the implementation of an $\mathrm{ECl}$ programme with its emphasis on early identification

A set of individual interviews with the participants in Group 2 was necessary in order to triangulate data, which brought different views on the current identification methods, referral systems and teamwork to the fore and therefore led to more accurate descriptions of the same aspects. Furthermore the PHC programme managers' opinion on the implementation of the different $\mathrm{ECl}$ functions within the PHC package was obtained. The apparatus used during all the interviews was an Olympus $\mathrm{VN}$ 240 PC digital voice recorder. The digital voice files were transcribed and securely stored on a laptop computer. The first author was the only person to have access to the data.

\section{Procedures}

\section{Reliability and validity}

With triangulation the reliability of the data was increased, as it was collected by means of different instruments and results could therefore be compared. Furthermore, two separate groups of participants were used to investigate the identification methods and referral systems, while the researcher's own field notes further supported the data obtained in the interviews.

A second reviewer was utilized to verify the interview recordings of both groups of participants. The reviewer listened to the recordings while reading the transcriptions. Discrepancies between the text and voice recordings were discussed until agreement was found between the researcher and second reviewer.

Face validity of the instruments was ensured as the format of the measuring instruments corresponded with the objectives of the research. All questions of the interview schedules were relevant and clearly formulated to ensure content validity. A senior speech-language therapist with working experience in primary health care reviewed the questionnaire and made suggestions to improve the relevancy of the questions.

\section{Pilot studies of the rating scale and interview schedules}

Pilot studies were conducted to test the rating scale and the two interview schedules in order to increase the accuracy and reliability of the data. According to the selection criteria, two PHC nurses and one PHC programme manager were selected to be part of the pilot studies. The rating scale and interview schedules were adapted according to the results obtained in the pilot studies.

\section{Procedures of the main study}

Based on the two strata, the different facilities to be included in the study were randomly selected from a total of $17 \mathrm{PHC}$ sites in the sub-district. Ditsobotla sub-district, previously named Lichtenburg is part of the Greater Taung local municipality and forms the central district in the North West Province. The district is largely rural and has an unemployment rate of over $50 \%$. The main industries are mining and quarrying, but agriculture is the focus (ESCOM, 2007).

During the first visit to a facility, permission was obtained to complete the rating scale. The researcher then filled in the rating scale without being intrusive. The completed rating scale was verified by one of the participants at each site so that a true report of the facility was stored for data analysis. After explaining the reason for the visit, the facility manager introduced the researcher to the potential participants in Group 1. Informed consent was obtained from the participants in Group 1 and the structured interviews were conducted according to the interview schedules. The interviews were conducted at the participants' working facilities, in order to ensure that the participants did not have to travel and that they would be as comfortable as possible. The interviews were conducted in a consultation room at the facilities

Thereafter the researcher visited the participants of Group 2 at the district office of Ditsobotla sub-district. Informed consent was obtained and the semi-structured interviews were conducted in each participant's office. This made the participants feel comfortable and little hindrance was present due to the professional environment in which the interviews were conducted.

\section{Data analysis}

The data of the structured interviews were analysed first, in order to determine which aspects needed further investigation and had to be included in the semi-structured interview schedule with participants of Group 2. The data obtained from the first interviews were analysed quantitatively according to the SAS system version 9.1 statistical computer software. As the analysis was done in Microsoft Excel, the data were stored electronically (Babbie, 2004).

Frequencies were calculated as data should be presented in a condensed form when the data consisted of a large number of observations (Steyn, Smit, Du Toit, \& Strasheim, 1998). Basic graphical presentations were used to better understand the data 
and decide where further statistical analysis would be appropriate. Fisher's exact test of independence was used for data with two attribute variables (Leedy \& Ormrod, 2005).

The rating scales were analysed numerically, as the data collection method was quantitative. Procedures similar to those used to analyse the data from the structured interviews were therefore used for the analysis of the rating scale.

In qualitative research the data analysis and interpretation are closely connected (Leedy \& Ormrod, 2005). This had to be taken into account when the results of the semi-structured interviews were analysed and interpreted. The researcher listened to the voice recordings and supplemented the transcriptions with field notes. Data were holistically read and re-read before the corpus was categorised according to themes. According to Leedy and Ormrod (2005) the researcher has to have a heightened and focused awareness of the data and subtle undercurrents during interviews have to be identified. Regularities were noted during the data analysis and categories of meaning emerged that could be presented as descriptive results.

\section{RESULTS AND DISCUSSION}

The results are presented and discussed in accordance with the objectives of the study.

The capacity of the facilities for implementing an early identification programme for infants at risk of disabilities

The basic features of the facility, the waiting rooms and consulting rooms were evaluated according to the rating scale (See Appendix A) and described to determine the possibility of implementing $\mathrm{ECl}$ functions in these facilities. Primary prevention activities, such as talks to caregivers to promote normal communication and emergent literacy development, can possibly be implemented in the waiting rooms of the facilities, while identification and intervention of infants and young children, i.e. primary and secondary prevention, may be implemented in the consultation rooms.

The checklist results indicated that all PHC facilities which were investigated had electricity and water supply, although some water shortages and power breaks occur. All buildings were permanent structures and three clinics were recently renovated. The travelling distance from Lichtenburg, the town in the centre of the sub-district, is not more than $35 \mathrm{~km}$. Most of the roads are not tarred and the public transport is by minibus taxis. The implication is that a speech-language therapist or an audiologist may be able to visit two clinics in close approximation on one day.

The results also indicated that not all facilities have the capacity to implement $\mathrm{ECl}$ functions in waiting rooms and/or consultation rooms, but patient information was adequately protected by means of secured filing cabinets. Six of the ten clinics had limited seating space in the waiting rooms, which means that educational talks may not be possible. None of the waiting rooms had posters or brochures on child development. Only five clinics had television monitors for educational videos.

As only a few of the facilities have the capacity for all ECl functions to be implemented, an incremental implementation of $\mathrm{ECl}$ services could be introduced. Speech-language therapists and audiologists therefore need to determine which levels of prevention can be implemented at which facilities in the sub-district. It may be possible that one facility only has the capacity to support the implementation of the primary prevention level in $\mathrm{ECl}$ services, while all three levels of prevention can be implemented at another facility. Since the waiting room capacity in the majority of the clinics was limited, it may imply that educational talks cannot be given and that only individual screening, assessment and intervention can be offered at the clinic. Promotion of communication development and other information may be given to caregivers in the form of brochures in the local language.

The availability, needs and limitations of human resources with-in the PHC context

A shortage of $\mathrm{PHC}$ personnel will have an impact on the incre mental implementation of $\mathrm{ECl}$ functions. Since the PHC personnel may not be able to assist the speech-language therapist and audiologist in some of the $\mathrm{ECl}$ functions, the capacity and support of the human resources at the facilities need to be determined in order to establish which $\mathrm{ECl}$ functions can be effectively implemented in the facilities.

According to the results there were community health nurses present at all the PHC facilities investigated, but not all were qualified at the time of the investigation. There were limited health care professionals such as doctors, speech-language therapists, audiologists and paediatricians working in the subdistrict. Although an inadequate arrangement, an itinerant doctor visited nine different PHC clinics at least once a week. The tenth PHC facility is a hospital where a permanent doctor was employed at the time of data collection.

The PHC personnel had limited knowledge regarding the availability of allied health care professionals at their facilities. The lack of knowledge of the different health care professionals working in the district may reflect an inadequate teamwork approach. Ineffective communication and collaboration between PHC nurses and other health care professionals, limited information regarding available services and no in-service training regarding the scope of practice of specialized services were further indicators that an inadequate teamwork approach is present in Ditsobotla sub-district.

It was estimated by the participants that, on average, approximately 165 infants were seen at the ten different PHC facilities on a daily basis. It is clear that the infant population of the subdistrict may be accessed through the PHC facilities. Limited human resources appear to be one of the reasons why screening for 
communication and hearing disorders was not carried out in Ditsobotla sub-district. The participants felt that it was the doctors' responsibility to screen for hearing and communication disorders in young children as they are trusted by caregivers. An interesting finding was that the participants felt that parents and family members share responsibility in identifying communication delays or disorders in the child's development.

Human resources and an adequate team approach appear to be limited in Ditsobotla sub-district. By implementing ECl activities on a primary prevention level at all PHC facilities the following may be achieved: introduction of Speech-language therapy and Audiology, promotion of $\mathrm{ECl}$ services to both the $\mathrm{PHC}$ professionals and the caregivers and provision of information on early identification, stimulation of infants and young children and communication developmental milestones. The introduction of $\mathrm{ECl}$ to the $\mathrm{PHC}$ professionals and caregivers may provide the basis on which the incremental implementation of other $\mathrm{ECl}$ activities, such as developmental surveillance, can be achieved at $\mathrm{PHC}$ facilities that have the capacity to accommodate such $\mathrm{ECl}$ activities. $\mathrm{ECI}$ implementation may be established by coordinating the services with certain PHC programmes, i.e. Non-personal health services, Disease prevention and control, Maternal, child and women's health, HIV/AIDS, sexually transmitted infections and tuberculosis, Mental health and substance abuse, and Health monitoring and evaluation.

\section{The early identification methods and resources currently used by the PHC personnel}

Posters on general health issues were numerous in the facilities, but posters on infant and child development were absent. There is a great need to develop mass communication material in Setswana and English for $\mathrm{ECl}$ in this sub-district which has to be addressed by speech-language therapists and audiologists. The results clearly indicated that none of the facilities had checklists to use for developmental surveillance and therefore it appeared that $\mathrm{PHC}$ professionals were not conducting any formal developmental screening of infants and young children. Appropriate checklists and case history forms for different South African contexts need to be developed so that children at risk of developmental delays can be successfully detected and referred within the PHC facilities (Department of Health, 2000).

The results indicated that PHC personnel use observation and that they talk to the child to determine if there is a problem in his/her communication development. Talking to the child to determine the level of communication development is a positive initiative, but the participants indicated that they do not have a guideline to assist them in identifying atypical development. The informal method of talking to the child which is currently used in the sub-district does not appear to be valid and the PHC personnel are in need of locally developed, valid, reliable and easy to use identification methods. The participants clearly indicated a need for formalized and valid identification methods and inservice training on how to identify infants and young children with communication delay or hearing impairment. The participants viewed their identification method as largely ineffective and unreliable.

Baby clinics, that form part of the Mother, Child and Women's Health Programme, were identified by the majority of the PHC personnel as the best $\mathrm{PHC}$ programme to implement the developmental surveillance of communication abilities in infants.

The referral systems used by PHC personnel to refer patients to speech-language therapists and audiologists.

According to Figure 1 the referral route is clear, but some difficulties in making referrals are experienced. A total of $80 \%$ of the participants indicated that they experienced time delays when patients had been referred. A disturbing finding was that caregivers of infants and young children were asked to come back a number of times before the referral to the speech-language therapist was made. The distances between patients' homes and the hospitals need to be taken into consideration, as patients usually cannot afford to travel far on a regular basis. Due to the

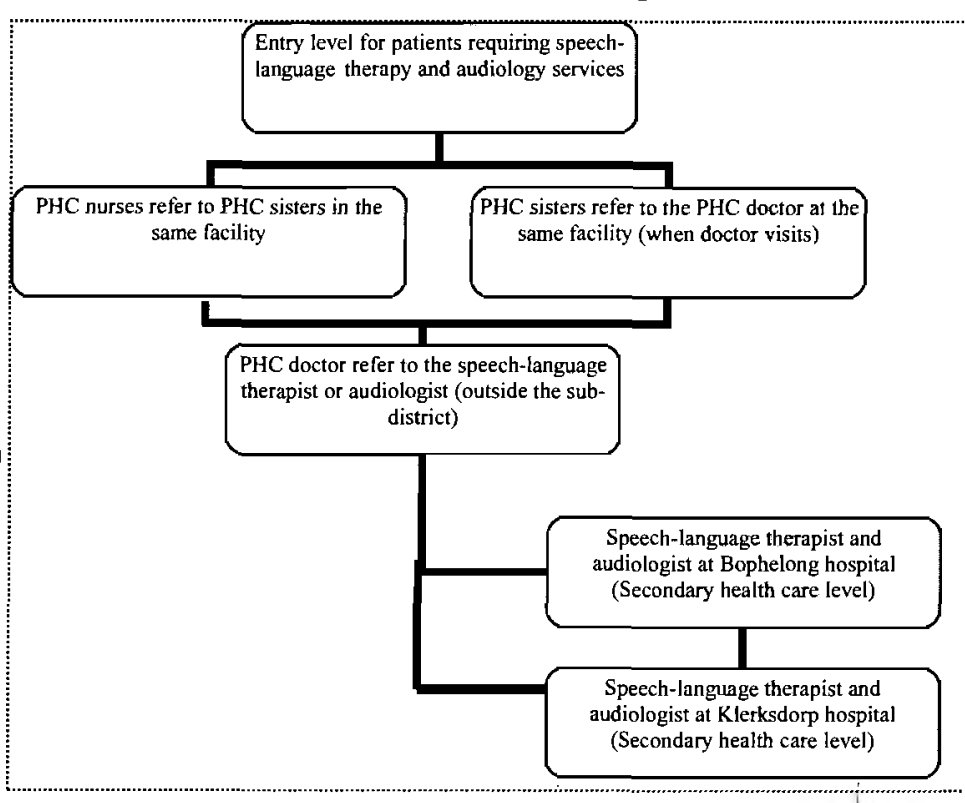

Figure 1. The referral process used by participants to refer patients for Speech-language therapy and Audiology services

large number of patients to be seen by speech-language therapists and audiologists and the transport problems, scheduled follow-up visits are irregular in the sub-district. Therefore it would be best for the patient to receive $\mathrm{ECl}$ services at the local clinic, instead of at the secondary health care hospital which may require further, more costly travel.

Participants in both Group 1 and 2 felt that the referral process was not effective and their reasons were as follows:

-ack of communication between professionals 
THE IDENTIFICATION PROCESS IN EARLY COMMUNICATION INTERVENTION FOLLOWED BY PRIMARY HEALTH CARE PERSONNEL IN DITSOBOTLA SUB-DISTRICT

The referral information is limited, resulting in the professional asking for the case history from the clinic

Few professionals, such as speech-language therapists, are currently working in the sub-district; thus only limited services are available in the district, and $\mathrm{PHC}$ personnel are uncertain of whether services are available

Referral books are not available for $\mathrm{ECl}$, and the $\mathrm{PHC}$ personnel do not get feedback after the referral has been made

Rong distances to the hospitals

The patients struggle with transport as they have little or no money for their trip

The PHC personnel receive little or no feedback from the speech-language therapists on their referrals

The doctors visit clinics only a few times every week, which delays the referral process as the patient is referred to the doctor for an appointment

The results from the current study indicated that few referrals were made to speech-language therapy and audiology services, which differs from developed contexts, such as the UK (Enderby \& Petheram, 2000). In the UK many patients are referred to local speech-language therapy and audiology services, but the referral process also faces certain challenges. Factors influencing the referral process in the UK include limited knowledge of the risk factors for communication delay, long waiting periods for appointments, epidemiological and demographic factors, such as long travelling distances (Enderby \& Petheram, 2000). The lack of human resources, financial constraints on families who need $\mathrm{ECl}$ services and limited teamwork as reasons for poor referrals may be specific to rural communities in developing contexts. The sug gestions for improvement of the referral process clearly indicate that the participants were concerned about the difficulties and are positive about the implementation of an effective referral system:

Administrative suggestion's:

$\square$ mproving back-referral system by implementing referral letters where back-referral is mandatory

Devising a simple and easy-to-use referral form on which patient information can be written with space provided for backreferral to the referring sister (in addition to the Road to Health Chart).

Fmployment of a full-time speech-language therapist in the sub-district

Provide feedback to the sub-district on the referral process and schedule regular meetingsiwith provincial and national coordinator in order to develop a new referral process

\section{Teamwork:}

Better communication and cooperation between professionals

Developing a team to address the needs of the infants and young children and their families in the community

\section{Information and training:}

Dmproving the awareness of the $\mathrm{PHC}$ personnel and training them in how to identify and refer infants and young children at risk for communication delay, instead of waiting for the doctor to make the referrals

Пnform the public regarding the services and initiate workshops for parents and teachers

The suggestions for improvement are useful to establish ECl services in the sub-district. Practical aspects as well as managerial and planning issues were included in the recommendations. It is clear that it was valuable to include the programme managers as participants in the research.

The current teamwork approach and participant views on the implementation of an early identification and referral programme, and the integration of $\mathrm{ECl}$ and the PHC programmes through collaborative activities

All the PHC personnel and PHC programme managers indicated that collaboration with other professionals would have a positive influence on case finding in $\mathrm{ECl}$. The PHC personnel indicated that collaboration would positively influence the identification and referral of infants and young children at risk for communication delay, as infants and young children can be identified earlier and time-delays can be decreased in the referral process. The inclusion of volunteers in collaboration with the PHC personnel in order to improve identification of infants at risk of communication delays needs to be explored further as volunteers can make regular home visits in the community to support families with special needs.

The majority of the PHC nurses indicated that teamwork should occur during early identification, referral and the early intervention phases of $\mathrm{ECl}$ service delivery. Consequently it is essential to establish commitment, competencies and a supportive environment to ensure an effective collaborative teamwork model, so as to positively reinforce the implementation of $\mathrm{ECl}$ services in Ditsobotla sub-district.

The PHC programme managers did not only provide relevant reasons for including the specific $\mathrm{ECl}$ function but also indicated the areas where collaboration should be implemented. The results indicated that the PHC programme managers have a clear understanding of $\mathrm{ECl}$ and of the importance of these services. Their knowledge of $\mathrm{ECl}$ may therefore positively influence the implementation of $\mathrm{ECl}$ functions by means of collaborative activi- 
ties in the district. Since they understand the importance of early identification and $\mathrm{ECl}$, the $\mathrm{PHC}$ programme managers appeared to be motivated and ready to assist in the implementation of such activities. Consequently it is important to build on the participants' interest in $\mathrm{ECl}$, which were stimulated by the current research project. The programme managers discussed how and why the different $\mathrm{ECl}$ functions should be implemented in Ditsobotla sub-district:

-To train mothers to stimulate their infants and children - The PHC programme managers indicated that this function will be beneficial to the infants as well as the mothers. To screen the communication and hearing abilities in young children - The majority of the PHC programme managers indicated that this function can be integrated in the programmes. The School Health programme was specified as a programme in which screening campaigns should be launched in order to identify young children in the following contexts: preschool playgroups, crèches and in primary school. The Health promotion programme does not need to be included in the screening of infants and young children. This function needs to be implemented at facility level and the speech-language therapist should work in collaboration with the facility managers.

-To determine risks for communication delay in young children and to provide intervention - The PHC programme managers indicated that this is an important function to be integrated as communication delays or disorders in infants and young children can be prevented or decreased. The programmes should be included in the implementation of $\mathrm{ECl}$ in the rural community as their resources are invaluable. Infants and young children in need of special services have to be referred as soon as possible. The Mother, Child and Women's and the School health programmes are implemented in contexts such as pre-schools where it is feasible to monitor the communication development of infants and young children.

-To advocate the education of children - The PHC programme managers indicated that communities should be made aware of the importance of education. This $\mathrm{ECl}$ function may improve the future of many children. The School health programme needs to operate in collaboration with the schools in order to promote the importance of education. All programmes should be involved in promotional initiatives and the Departments of Health and Education need to collaborate.

-To facilitate the implementation of a language and literacybased preschool curriculum to ensure school readiness - All the PHC programme managers supported the integration of this function into the PHC programmes. The Departments of Health and Education need to collaborate on school readiness. The educators should be trained to stimulate the communication develop- ment of young children and facilitate the skills to be acquired at preschool level. Early learning centres and crèches should be visited in collaboration with the School health programme. The training of the preschool personnel may also assist in identifying infants and young children at risk for communication delays.

-To evaluate and monitor the collaborative activities - The PHC programme managers explained that it is very important to demonstrate progress and to identify the problem areas which may exist. Statistics need to be monitored and the goals of the activities have to be kept in mind. The effectiveness of teamwork has to be evaluated and the PHC programme managers have to have regular meetings in order to monitor progress in a collaborative way.

-Community awareness campaigns on $\mathrm{ECl}$ services and participation in health calendar day activities - The ECl programme should be integrated in the community by collaboration with the other PHC programme initiatives. The importance of community campaigns as a way to provide focused information and to introduce new programmes to people was emphasized by the PHC programme managers.

\section{CONCLUSION AND IMPLICATIONS}

Since case finding and referrals are inadequate and ECl services have not yet been established in Ditsobotla sub-district, certain limitations can be expected. The study found that the identification methods for infants at risk of communication delay or disorders are limited and unreliable, and that the referral system appears to be ineffective in this impoverished rural district. Against the background of difficulties to establish $\mathrm{ECl}$ services in South Africa, identified by Kritzinger (2000), it appears that identification and referral are but two aspects of many influencing $\mathrm{ECl}$ service delivery. Inadequate access to $\mathrm{ECl}$ facilities, the scarcity of facilities, limited knowledge about the benefits of $\mathrm{ECl}$ among caregivers and health care professionals, and limited employment of early communication interventionists (Kritzinger, 2000) are other aspects which impact negatively on the professional obligation to expand $\mathrm{ECl}$ services in South Africa.

In order to improve service delivery in rural areas and therefore make services more accessible to the communities, the findings indicated that the integration of $\mathrm{ECl}$ functions within the $\mathrm{PHC}$ package is feasible. The results of the study found an interest in $\mathrm{ECl}$ among primary health care personnel and managers and a positive attitude to improve services. A formal approach to implementation was suggested, and collaborative partnerships between management, $\mathrm{PHC}$ programme managers and $\mathrm{PHC}$ personnel are feasible in the sub-district. The incremental rollout of $\mathrm{ECl}$ activities at PHC facilities may also improve teamwork, as collaboration is essential to improve the efficacy of early identification and referrals.

Kritzinger (2000) also described limited teamwork and limited 

knowledge of $\mathrm{ECl}$ as problem areas in service delivery. The implementation of collaborative activities necessitates a commitment to integrated teamwork by all involved. The results of the current study showed a remarkable motivation by the participants for the implementation of ECl. Training of PHC personnel in $\mathrm{ECl}$ services and promotion of normal communication and literacy development among young children form part of the different ECI primary prevention functions. These functions may be phased in at PHC facilities with sufficient capacity and human resources. Furthermore, training packages must be developed to address the information needs experienced by PHC professionals, volunteers, parents and caregivers.

The implementation of $\mathrm{ECl}$ functions within the $\mathrm{PHC}$ package may address some of the multiple problem areas in $\mathrm{ECl}$ service delivery in South Africa. The implementation of ECl services in rural areas in South Africa needs to be considered holistically, and the different programmes within the PHC package should be used as a means to reach the communities.

Since the introduction of $\mathrm{ECl}$ guidelines for speech-language therapists and audiologists in South Africa by Louw (1997), a theoretical framework for service delivery in the public sector has been described (Kritzinger \& Louw, 2003). This framework provides a basis to assist in the planning of $\mathrm{ECl}$ implementation. However, the potential of $\mathrm{ECl}$ to prevent and minimise communi- cation disabilities is not yet impacting on the South African health care system, especially in a rural district such as Ditsobotla. The current research study indicated that difficulties may be addressed by means of integrating $\mathrm{ECl}$ functions into the PHC package. A diagrammatic representation of the proposed integration is provided in Figure 2.

\section{ECI Entry level - determine capacity of facilities,} human resources and needs of community

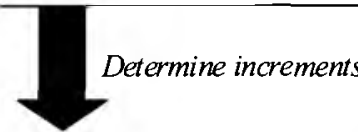

$\mathrm{ECI}$ FUNCTIONS IN PRIMARY PREVENTION

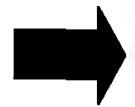

NON-PERSONAL

HEALTH SERVICES

- Promotion of normal development

-Developmental surveillance

Planning increments

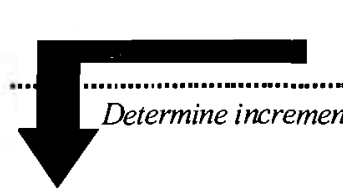

Planning increments

HEALTH MONITORING \& EVALUATION

Monitor incrememts

$\mathrm{ECI}$

FUNCTIONS IN SECONDARY

PREVENTION

\section{DISEASE PREVENTION AND CONTROL}

- Providing ECI and parent training

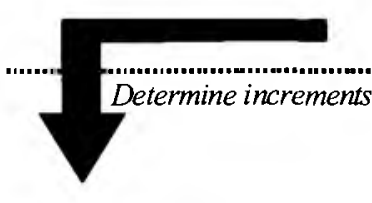

ECI

FUNCTIONS IN TERTIARY PREVENTION
Planning increments

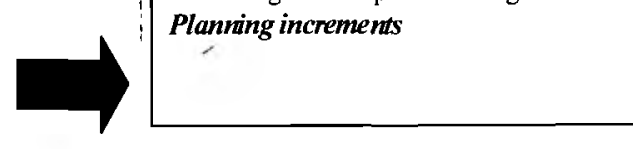

HEALTHMONITORING \& EVALUATION Monitor increments

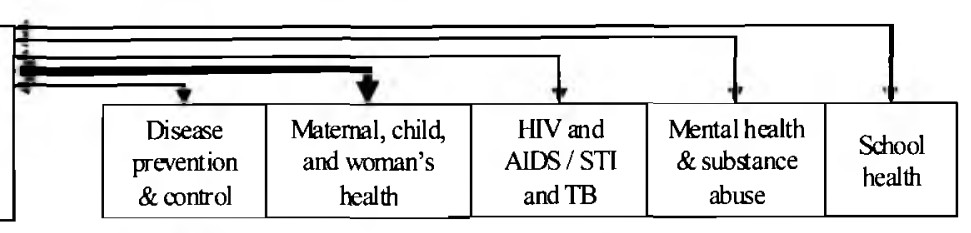

Implementing increments
DISEASE PREVENTION AND CONTROL

- Rehabilitation of disabilities

Planning increments

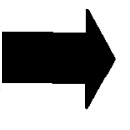

HEALTH MONITORING \& EVALUATION
Monitor increments
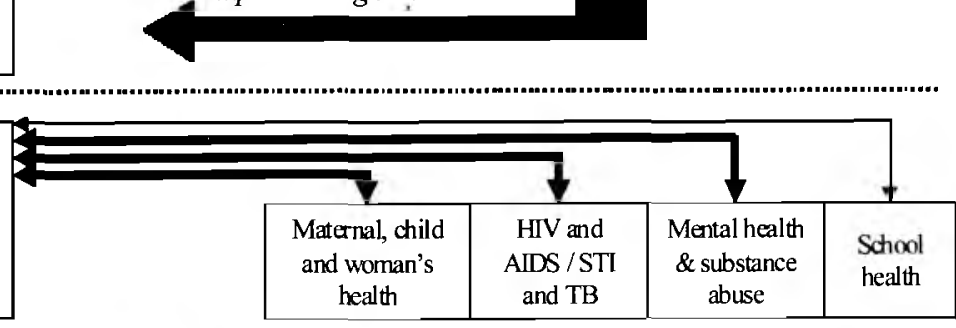


\section{REFERENCES}

Babbie, E. (2004). The practice of social research. (I0th ed.). Belmont: Wadsworth.

De Vos, A.S. (2005). Combined quantitative and qualitative approach. In A.S. de Vos (Ed.). Research at grass roots. For the social sciences and human service professions. ( $3^{\text {rd }}$ ed.). (pp357-365) Pretoria: Van Schaik.

Department of Health (2000). The primary health care package for South Africa - a set of norms and standards. Pretoria: Department of Health.

Dennis, M. (2000). Developmental plasticity in children: the role of biological risk, development, time and reserve. Journal of Communication Disorders, 33:321-332.

Emmett, T. (2005). Disability and poverty. In E. Alant \& L.L. Lloyd (Eds.). Augmentative and alternative communication and severe disabilities. Beyond poverty. (pp68-94)London and Philadelphia: Whurr Publishers.

Enderby, P. \& Petheram, B. (2000). An analysis of referrals to speech and language therapy in 11 centres, 1987-1995. International Journal of Language and Communication Disorders, 35(2):137-146.

Equity project (2000). Case study series: Referrals from primary health care clinics in the Eastern Cape Province. Retrieved April, 2005 from http://www.doh.gov.za/docs/factsheets/ guidelines/dhp/part4g.pdf .

ESCOM. (2007) Social impact assessment report. Retrieved August 2009 from http://www.escom.co.za/content/Appendix\% 201 10\%/20social\%20Assessment\%20Report.pdf.

Fair, L. \& Louw, B. (1999). Early communication intervention within a community-based intervention model in South Africa. The South African Journal of Communication Disorders, 46: 1323.

Fouché, C.B. \& De Vos, A.S. (2005). Quantitative research designs. In A.S. de Vos (Ed.). Research at grass roots. For the social sciences and human service professions. (3rd ed.). (pp132-143) Pretoria: Van Schaik.

Greeff, M. (2002). Information collection: interviewing. In A.S. de Vos (Ed.). Research at grass roots. For the social sciences and human service professions. (2nd ed.) (pp291-320). Pretoria: Van Schaik.

Kritzinger, A.M. (2000). Establishing a computer-based data system for early communication intervention in South Africa. Unpublished doctoral thesis. Pretoria: University of Pretoria.

Kritzinger, A.M. \& Louw, L. (2003). Clinical training of undergraduate Communication Pathology students in neonatal assessment and neonate-caregiver interaction in South Africa. The South African Journal of Communication Disorders, 50: 5-14.

Kritzinger, A., Louw, B. \& Rossetti, L.M. (2001). A transdisciplinary conceptual framework for the early identification of risks for communication disorders in young children. The South African Journal of Communication Disorders, 48, 33-44.

Leedy, P.D. \& Ormrod, J.E. (2005). Practical research: Planning and design. ( $8^{\text {th }}$ ed.). New Jersey: Pearson Merrill Prentice Hall. Lequerica, M. (1997). Toward a One-Stop Model of Service for Low-Income Preschoolers: Insights from Clinical Practice and Research. Infant-Toddler Intervention. The Transdisciplinary Journal, 7(4): 285-300.

Louw, B. (1997). Early communication intervention: Guidelines for speech-language therapists and audiologists. SASLHA: Eth- ics and Standards Committee.

Moodley, L. (1999). An in-service training programme for community nurses in the identification of at risk infants and toddlers. Unpublished Masters thesis. Pretoria: University of Pretoria.

North West Department of Health. (2003). Referral framework document. Mafikeng.

Pickering, M., McAllister, L., Hagler, P., Whitehill, T.L., Penn, C., Robertson, S.J., \& McCready, V. (1998). External factors influencing the profession in six societies. American Journal of Speech-Language Pathology, 7, 4: 5-17.

Plante, E. \& Beeson, P. M. (2004). Communication and communication disorders. A clinical introduction. ( $2^{\text {nd }}$ ed.). Boston: Pearson.

Rossetti, L.M. (2001). Communication intervention. Birth to three. ( $2^{\text {nd }}$ ed.). Canada: Singular Thomson Learning.

Steyn, A.G.W., Smit, C.F., Du Toit, S.H.C., \& Strasheim, C. (1998). Moderne statistiek vir die praktyk. (6 $6^{\text {th }}$ ed.). Pretoria: Van Schaik.

Strydom, H. \& Venter, L. (2002). Sampling and sampling methods. In A.S. de Vos (Ed.). Research at grass roots. For the social sciences and human service professions. ( $2^{\text {nd }}$ ed.) (pp 197209). Pretoria: Van Schaik.

Swanepoel, D.C.D. (2004). Infant hearing screening at maternal and child health clinics in a developing South African community. Unpublished doctoral thesis. Pretoria: University of Pretoria.

Van Rensburg, H.C.J. (2004). National health care systems: Structure, types and dynamics. In H.C.J. van Rensburg (Ed.). Health care in South Africa. (pp1-50)-Pretoria: Van Schaik.

Werner, E. E. (2000). Protective factors and individual resilience. In J. P. Shonkoff, \& S. J. Meisels (Eds.). Handbook of early childhood intervention ( $2^{\text {nd }}$ ed.) (pp115-132). London: Cambridge University Press. 


\section{APPENDIX A \\ Rating scale for the description of human and physical resources at clinics/hospitals}

Name of clinic/ hospital ward

Population of children under 5 years served by this clinic/ward:

Doctors: Number

Nursing staff: Number

Nurses in training: Number

Number of visits per week by:

Doctors

Speech-language therapist \& Audiologist

Occupational therapist

Dietician

Physiotherapist

Paediatrician

Other health care workers

\begin{tabular}{|c|c|c|c|c|}
\hline $\begin{array}{l}\text { Areas of } \\
\text { evaluation }\end{array}$ & Limited & Adequate & Good & Comments \\
\hline \multicolumn{5}{|l|}{$\begin{array}{l}\text { Water supply- water } \\
\text { supply at facility }\end{array}$} \\
\hline \multicolumn{5}{|l|}{$\begin{array}{l}\text { Electricity- } \\
\text { provision of } \\
\text { electricity }\end{array}$} \\
\hline \multicolumn{5}{|l|}{$\begin{array}{l}\text { The average number } \\
\text { of infants the sister } \\
\text { sees daily }\end{array}$} \\
\hline \multicolumn{5}{|l|}{$\begin{array}{l}\text { Toys available for } \\
\text { developmental } \\
\text { screening }\end{array}$} \\
\hline \multicolumn{5}{|c|}{ General impression of waiting rooms } \\
\hline \multicolumn{5}{|c|}{\begin{tabular}{l|l} 
1. Seating for & \\
patients & \\
\end{tabular}} \\
\hline \multicolumn{5}{|l|}{$\begin{array}{l}\text { 2. Posters on } \\
\text { general health } \\
\text { issues }\end{array}$} \\
\hline \multicolumn{5}{|l|}{$\begin{array}{l}\text { 3. Posters on the } \\
\text { development of } \\
\text { infants }\end{array}$} \\
\hline \multicolumn{5}{|c|}{ General impression of consulting rooms } \\
\hline \multicolumn{5}{|c|}{\begin{tabular}{l|l} 
1. Space for & \\
confidential & \\
interviews with & \\
parents/mothers &
\end{tabular}} \\
\hline \multicolumn{5}{|l|}{$\begin{array}{l}\text { 2. Desk and chairs } \\
\text { for PHC personnel }\end{array}$} \\
\hline \multicolumn{5}{|l|}{$\begin{array}{l}\text { 3. Medicine } \\
\text { cabinets }\end{array}$} \\
\hline \multicolumn{5}{|l|}{$\begin{array}{l}\text { 4. Posters on } \\
\text { general health } \\
\text { issues }\end{array}$} \\
\hline \multicolumn{5}{|c|}{\begin{tabular}{l|l} 
5. Posters on the & \\
development of \\
infants
\end{tabular}} \\
\hline \multicolumn{5}{|c|}{ General impression of reception area } \\
\hline $\begin{array}{l}\text { 1. Filing cabinets to } \\
\text { ensure } \\
\text { confidentiality of } \\
\text { patient files }\end{array}$ & & & & \\
\hline
\end{tabular}

